\title{
Mental health services for children in China during the COVID-19 pandemic: results of an expert-based national survey among child and adolescent psychiatric hospitals
}

\author{
Yonghua Cui ${ }^{1} \cdot$ Ying Li $^{1} \cdot$ Yi Zheng $^{2}$ - Chinese Society of Child \& Adolescent Psychiatry
}

Published online: 11 May 2020

○) Springer-Verlag GmbH Germany, part of Springer Nature 2020

\section{Background}

An outbreak of coronavirus disease 2019 (COVID-19) occurred in Wuhan (Hubei, China) at the end of 2019, and subsequently spread worldwide. Currently, over 200 countries and 2,000,000 people are infected by COVID-19 [1]. In China, a large number of hospitals have to take precautions to prevent the further spread of COVID-19. Medical services have been affected seriously, and numerous patients with many disorders/diseases have had to cancel their original plans to be hospitalized [2]. With the outbreak of COVID-19, mental health care has attracted more attention, especially for children [3], begging several questions: how to provide mental health care to children diagnosed with COVID-19, how to take care of non-infected children during quarantine? How much has the COVID-19 pandemic affected mental health services in China and how to provide regular services to youths with mental disorders? To address these issues, the Chinese Society of Child \& Adolescent Psychiatry conducted a survey on the situation of hospitals which provide mental health services for children in China; data were ascertained between March 20 and April 1. Moreover, experts' suggestions for mental health care of children during the pandemic were also collected. To state

Yonghua Cui

cuiyonghua@bch.com.cn

$\bowtie$ Ying Li

liying@bch.com.cn

$\triangle$ Yi Zheng

yizheng@ccmu.edu.cn

1 Department of Psychiatry, Beijing Children's Hospital, Capital Medical University, National Center for Children's Health, 56 Nanlishi Road, Beijing 100101, China

2 Beijing Anding Hospital, Capital Medical University, No. 5 Ankang Hutong Deshengmen Wai, Xicheng District, Beijing 100088, China the suggestions for different groups of children clearly, the term "infected children" is defined as the children diagnosed with COVID-19 and the term "affected children" is defined as non-infected children who suffer home quarantine, social distancing, school closures, anxiety, etc. during the outbreak of COVID-19.

\section{Mental health services for children in China during the COVID-19 outbreak}

Several studies have been published to provide suggestions for mental health care for affected people in China [3-5]. However, the extent to which childhood mental health services are affected by COVID-19 is still unclear. Therefore, a national survey, including 33 hospitals, which provide mental health services to both child and adolescent outpatients and/or inpatients (the total number of such hospitals in China amounts to almost 50), was performed to investigate the situation of children's mental health services during COVID-19 in early March 2020.

According to our national survey, $9 \%(n=3)$ of hospitals closed their outpatient units. The total number of outpatient visits dropped to $53 \%$ of that of the pre-COVID-19 outbreak. Inpatient referrals declined by $50 \%$ and nearly $25 \%$ of hospitals closed inpatient wards. $85 \%$ of the hospitals prepared isolation wards to receive newly hospitalized patients to avoid potential contagion of already admitted youths. We performed correlation analysis to assess the impact of the distance from Wuhan on percent reduction of inpatient/outpatient services. We found a significant inverse correlation for outpatients $(r=-0.463, p<0.01)$ and even more so for inpatients $(r=-0.709, p<0.001)$.

Fortunately, none of the hospitals reported child psychiatrists/nurses/other employees of the respective childhood mental health services as being infected with COVID-19 (Table 1). 
Table 1 Effect of the COVID19 pandemic on Child and Adolescent Mental Health Services in China

\begin{tabular}{|c|c|c|c|c|}
\hline Hospitals & $\begin{array}{l}\text { Reduction of outpa- } \\
\text { tient visits in } \%\end{array}$ & $\begin{array}{l}\text { Reduction of inpatient } \\
\text { admissions in } \%\end{array}$ & $\begin{array}{l}\text { Established isola- } \\
\text { tion wards }\end{array}$ & $\begin{array}{l}\text { The distance from } \\
\text { Wuhan in kilom- } \\
\text { eters }\end{array}$ \\
\hline Hospital 1 & $20 \%$ & $15 \%$ & Yes & 2330 \\
\hline Hospital 2 & $50 \%$ & $25 \%$ & Yes & 1808 \\
\hline Hospital 3 & $80 \%$ & $15 \%$ & Yes & 1197 \\
\hline Hospital 4 & $80 \%$ & $80 \%$ & Yes & 335 \\
\hline Hospital 5 & $33.3 \%$ & $25 \%$ & Yes & 1150 \\
\hline Hospital 6 & $50 \%$ & $60 \%$ & Yes & 974 \\
\hline Hospital 7 & $20 \%$ & $30 \%$ & N/A & 673 \\
\hline Hospital 8 & $55.5 \%$ & $80 \%$ & Yes & 820 \\
\hline Hospital 9 & $90 \%$ & $80 \%$ & Yes & 342 \\
\hline Hospital 10 & $25 \%$ & $30 \%$ & Yes & 938 \\
\hline Hospital 11 & $60 \%$ & $80 \%$ & Yes & 510 \\
\hline Hospital 12 & $87 \%$ & N/A & Yes & 348 \\
\hline Hospital 13 & $90 \%$ & $60 \%$ & Yes & 895 \\
\hline Hospital 14 & $40 \%$ & N/A & N/A & 846 \\
\hline Hospital 15 & $30 \%$ & N/A & N/A & 2189 \\
\hline Hospital 16 & N/A & $95 \%$ & N/A & 740 \\
\hline Hospital 17 & $75 \%$ & N/A & N/A & 763 \\
\hline Hospital 18 & $80 \%$ & N/A & N/A & 785 \\
\hline Hospital 19 & $67 \%$ & $70 \%$ & Yes & 542 \\
\hline Hospital 20 & $50 \%$ & N/A & Yes & 715 \\
\hline Hospital 21 & N/A & N/A & Yes & 398 \\
\hline Hospital 22 & $10 \%$ & N/A & Yes & 1054 \\
\hline Hospital 23 & $25 \%$ & $50 \%$ & Yes & 876 \\
\hline Hospital 24 & $90 \%$ & N/A & N/A & 1149 \\
\hline Hospital 25 & $70 \%$ & N/A & N/A & 887 \\
\hline Hospital 26 & $35 \%$ & $75 \%$ & N/A & 775 \\
\hline Hospital 27 & $50 \%$ & $60 \%$ & N/A & 1033 \\
\hline Hospital 28 & $50 \%$ & N/A & Yes & 841 \\
\hline Hospital 29 & $80 \%$ & $80 \%$ & Yes & 355 \\
\hline Hospital 30 & $50 \%$ & $60 \%$ & Yes & 792 \\
\hline Hospital 31 & N/A & N/A & Yes & 0 \\
\hline Hospital 32 & $0 \%$ & $0 \%$ & Yes & 1205 \\
\hline Hospital 33 & $50 \%$ & $25 \%$ & Yes & 865 \\
\hline Total (Mean) & $53.09 \%$ & $50.00 \%$ & $69.70 \%$ & 882.73 \\
\hline
\end{tabular}

N/A data not available

\section{Initial contact of children/adolescents with hospitals for provision of mental health services}

To reduce the spread of COVID-19 in hospitals, most hospitals in China have adopted a new medical management process for patients seeking mental health care [6]. Based on the online meeting of the Chinese Society of Child \& Adolescent Psychiatry on April 2, we planned this process and gave suggestions to the respective hospitals accordingly (Fig. 1). This medical process is applied to both inpatients and outpatients. When young patients come to hospitals for mental health services, they and their parents are required to provide information on signs of infection. The most basic and important step is taking body temperature. If temperature surpasses $37.3{ }^{\circ} \mathrm{C}$, children and their parents are tested for COVID-19 infection. All newly admitted inpatients receive regular hospital treatments in the isolation ward for at least 14 days. They are then transferred to normal wards to continue their treatments. They are not allowed to be visited by their parents during the entire inpatient treatment; online contacts are recommended. Medical employees working in the isolation ward wear masks, gowns, goggles and gloves, while they only wear masks in the normal wards. Some of these 


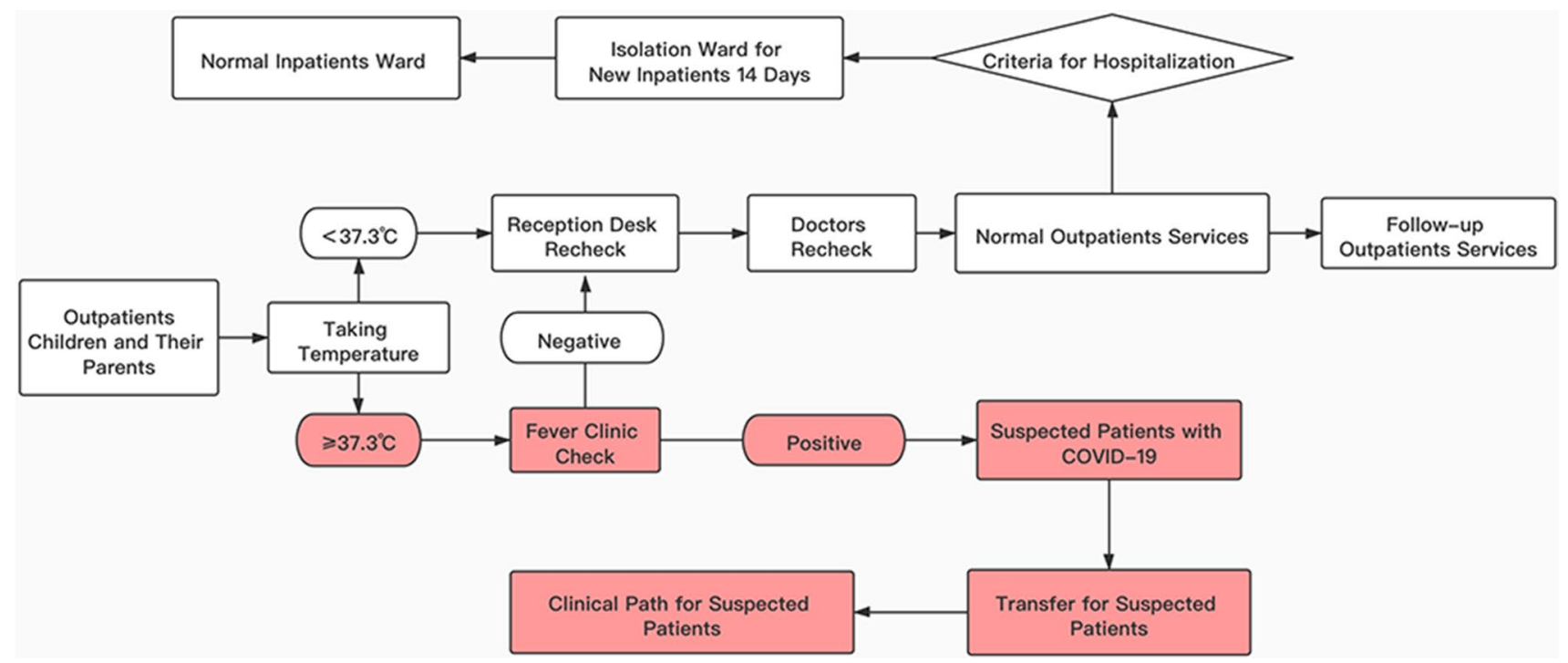

Fig. 1 The medical process applied to both child and adolescent inpatients and outpatients of mental health services in China

hospitals enabled medical employees to live and work in the hospitals until the end of the outbreak of COVID-19.

\section{Provision of online services}

Provision of online mental health services is safe. With the popularization of internet services and smartphones, as well as the emergence of fifth-generation $(5 \mathrm{G})$ mobile networks, mental health professionals and health authorities have been in a position to provide online mental health services during the COVID-19 outbreak. To date, several types of online mental health services have been implemented widely for those in need during the outbreak in China [7]. Take Beijing Children's Hospital, for example, which has initiated online medical services including the mental health services by an app in smartphones. Importantly, the staff of a hospital in Wuhan has provided online mental health counseling services for 2144 affected children in Wuhan from February 20 to March 5 . Forty-five percent of these patients reported anxiety, $22 \%$ insomnia, $13 \%$ symptoms of depression, and $13 \%$ somatic complaints. $8 \%$ reported other problems. Online services might be the most suitable method to provide mental health care for children affected by COVID-19 [7]. It should be noted that online services for child and adolescent mental disorders had existed to a minimum extent only prior to the COVID-19 outbreak. However, based on our survey, over $15 \%$ of the 33 hospitals newly opened the online services for children and adolescents with mental disorders.

\section{Mental health care for infected children who have more or less severe mental problems}

In a report covering the epidemiological characteristics of the 2019 outbreak of COVID-19 up to February 11, it was estimated that approximately 1000 individuals $\leq 20$ years have been infected by the virus in China, with half of them aged $\leq 10$ years [8]. It is the official policy in China to hospitalize all children/adolescents infected with COVID-19; the same applies to infected adults.

When children are diagnosed as COVID-19 positive, they are transferred to designated pediatric hospitals, and if their parents, as is usually the case, are also infected with COVID-19, these, too, will be transferred to designated hospitals for adults. Moreover, close contacts (including non-infected parents) will also be transferred to quarantine centers and stay there for at least 14 days. Therefore, the infected children necessarily face separation from their parents to stay in an isolation ward; they do not have contact with other infected children in the same ward. The hospitalization is mandatory to enable medical supervision and to prevent the spread of the virus. Wuhan Children's Hospital is the largest hospital to admit children infected with COVID-19 in Wuhan. One of the team experts from this hospital reported that, based on his clinical observations, the most common mental problems of infected children were separation anxiety and insomnia.

Notably, the Chinese government has recently offered guidelines on psychological interventions for infected people [9]. However, the guidelines for children were less detailed. There are several other suggestions for 
psychological aid to children infected with COVID-19. First, child psychiatrists might be the perfect candidates to provide mental health care to these children. Due to the lack of child and adolescent psychiatrists in China, the online work model is suggested. But for the infected children who showed signs signaling mental problems (Table 2) [10], child psychiatrists can work directly with the young patients and their families using adequate protection. Second, the provision of mental health care should last until the child recovers from COVID-19. Importantly, it has been reported that more than $10 \%$ of children who have experienced trauma due to the infection and its consequences might be diagnosed with posttraumatic stress disorder (PTSD) [11]. Thus, screening for PTSD may be necessary for some child patients who showed nightmares or unwanted memories of the trauma, avoidance of situations that bring back memories of the trauma, heightened reactions and so on. The content of the mental health regimen should include assessment, building of a therapeutic alliance, ranking infected children by the severity of mental and COVID-19 symptoms, formulating and enacting individual psychological plans, and providing crisis invention and any appropriate medication.

\section{Suggested mental health care for children quarantined at home}

During the outbreak of COVID-19 in China, there has been a nationwide school closure. It is estimated that there are more than 220 million children and adolescents who must remain home with their parents [12]. We need to pay more attention to mental health problems of children quarantined at home. These children may experience fear of infection, frustration and boredom, inadequate information, lack of in-person contacts with classmates, friends, and teachers, and lack of personal space at home and of outdoor activities. If applicable, parental unemployment and COVID-19 outbreak-related family financial losses can have even more problematic and enduring effects on children and adolescents [3].

Recently, the Chinese Society of Child \& Adolescent Psychiatry conducted an online survey addressed at parents of young patients (aged 6-12; $N=2355$ ) to investigate the situation of quarantined children in Beijing. $67 \%$ of parents reported difficulties in managing their children.

Furthermore, online school courses have been assigned to such children in Beijing, but only $58 \%$ of children finish their assigned online courses. $21 \%$ of parents reported that their children showed anxiety related to COVID19. For the children with anxiety related to COVID-19, online psychological aid may be the most suitable type of help [7]. The psychological aid should be provided to both parents and the children. Its contents addressed at parents include two aspects: first, management of the children's behaviors including regular sleep, avoidance of unhealthy diets, appropriate exercise, and parental help to finish homework; second, dealing with the anxiety of children, including emotion expression, and family activities. Parents are informed to keep their emotions "stable", especially upon management of their children's behaviors. For anxiety symptoms of children, building a close relationship with the online therapist is the most important step; online video game therapy might be suitable for most quarantined children $[13,14]$.

Additionally, children with mental disorders need to be monitored closely. For example, due to deranged mental health services, some children with mental disorders were unable to obtain their medicine, which may lead to a deterioration of their mental disorder. Providing services via online pharmacies can help in these circumstances.
Table 2 Warning signs of mental health problems in COVID-19-infected children

\begin{tabular}{|c|c|}
\hline Symptoms & Detailed description \\
\hline Abnormalities in daily tasks & $\begin{array}{l}\text { - Sleep problems such as sleeps all day or refuses to sleep } \\
\text { - Refuses to eat or eats too much } \\
\text { - Stops talking with parents or familiar medical staff }\end{array}$ \\
\hline Mood swings & $\begin{array}{l}\text { - Increased aggression or fear } \\
\text { - Depression symptoms or anxiety }\end{array}$ \\
\hline Abnormal behaviors & $\begin{array}{l}\text { - Inappropriate behavior like refusing treatments } \\
\text { - Out-of-control behavior such as hurting medical staff } \\
\text { - Self-harm behavior } \\
\text { - Cannot stop complaining }\end{array}$ \\
\hline Psychosis-like symptoms & $\begin{array}{l}\text { - Unable to recognize family or friends } \\
\text { - Has strange ideas or cannot understand other people } \\
\text { - optical or auditory hallucinations }\end{array}$ \\
\hline Somatic symptoms & $\begin{array}{l}\text { - Feeling "uncomfortable" for no reason } \\
\text { - Increase in headaches and stomach aches without apparent cause }\end{array}$ \\
\hline
\end{tabular}




\section{Escalating tensions in Chinese parent-child relationships during the COVID-19 outbreak}

A recent report on mitigating the effects of home confinement on children stated that home confinement could offer an excellent opportunity to work on and improve interactions between parents and children [3]. However, when parents have to take the roles of both caregiver and teacher during home quarantine, there can be conflicts [15].

From a mental health perspective, there are three possible reasons for this phenomenon. First, the public health crisis can raise anxiety levels in both parents and children. Second, many Chinese parents tend to overlook or are unaware of their children's mental health status. For example, due to the lack of knowledge about children's mental health, many parents have problems differentiating normal and abnormal behavioral and emotional problems in their children. Third, parenting style plays a critical role in children's mental health [16], and a large proportion of Chinese parents use the authoritative style, which does not focus on cultivating skills to cope with this type of crisis for children. Overall, the parent-child relationship has shown a close association with the mental health of children. With the outbreak of COVID-19 in China, this relationship is facing further challenges.

The current escalating conflict in the Chinese parent-child relationship is just a superficial phenomenon related to the underlying challenges of children's mental health in China. It highlights the lack of mental health education for children and limited popular knowledge of mental health issues among parents.

\section{Mental health of medical staff involved in the prevention and treatment of COVID-19}

The medical staff involved in the prevention (working in the quarantine centers) and treatment (working in the designated hospitals) of COVID-19 patients face a high risk of infection as well as concerns of bringing the virus to their homes [17]. They might suffer psychological problems under this stress, especially anxiety and depression [18].

Therefore, to investigate the mental health situation of medical staff involved in the prevention and treatment of COVID-19-positive adult patients, we conducted an online survey to investigate the anxiety and depression symptoms of the exposed medical staff in Beijing. The Generalized Anxiety Disorder Scale-7 (GAD-7) [19] and the Patient Health Questionnaire-9 (PHQ-9) [20] were used to assess the anxiety and depression symptoms. A total of 892 medical workers completed the online questionnaire between March 20 and April 1, most being under the age of $40(75 \%)$, with a bachelor's degree (61\%) and married (73\%). Among them, 39\% had anxiety symptoms (GAD-7 score $>4$ ), and $33 \%$ had depression symptoms (PHQ-9 score $>4$ ) during the COVID-19 outbreak. These results indicate that we need to pay more attention to psychological assistance for medical staff. Protecting the mental health of these medical workers is also very important not only for the control of the epidemic but also for their long-term health.

\section{Conclusion}

China has put much effort into improving public mental health, including offering mental health support and building a network to provide these services, training psychologists and psychiatrists, and improving the quality of services provided by schools and community centers [21]. However, the COVID-19 outbreak has brought new challenges that must be addressed. Importantly, there were no national guidelines covering interventions for major public health crises affecting children. Building a national service network system might be a suitable goal for the future. This network should include governmental agencies, public health institutions, hospitals, schools, community centers, and individual families. The government would formulate the policy, public health professionals would design the details of the programs, hospitals would provide services for some serious cases, and community centers and families would take charge of less seriously affected cases and the long-term follow-up mental health care. Through such a service network, crisis invention services could be provided rapidly and thoroughly during public health crises. The scarcity of child psychiatrists in China is an urgent problem that must be addressed [22]. Government policies that would encourage more medical students to step into this rapidly developing field and to build high-quality training systems for child psychiatrists are both suitable strategies.

Acknowledgements All the members of Chinese Society of Child \& Adolescent Psychiatry finished the survey and participated in the meeting mentioned in this manuscript. For this manuscript, Yi Zheng took the initiative, Yonghua Cui performed the survey, and Ying Li finish the draft. Johannes Hebebrand as the Editor-in-Chief of European Child and Adolescent Psychiatry gave detailed suggestions to this article.

\section{Compliance with ethical standards}

Conflict of interest None. 


\section{References}

1. Chinazzi M, Davis JT, Ajelli M, Gioannini C, Litvinova M, Merler $S$ et al (2020) The effect of travel restrictions on the spread of the 2019 novel coronavirus (COVID-19) outbreak. Science. https:// doi.org/10.1126/science.aba9757

2. Zu ZY, Jiang MD, Xu PP, Chen W, Ni QQ, Lu GM et al (2020) Coronavirus disease 2019 (COVID-19): a perspective from China. Radiology. https://doi.org/10.1148/radiol.2020200490

3. Wang G, Zhang Y, Zhao J, Zhang J, Jiang F (2020) Mitigate the effects of home confinement on children during the COVID-19 outbreak. Lancet. https://doi.org/10.1016/S0140-6736(20)30547 $-\mathrm{X}$

4. Yang Y, Li W, Zhang Q, Zhang L, Cheung T, Xiang YT (2020) Mental health services for older adults in China during the COVID-19 outbreak. Lancet Psychiatr. https://doi.org/10.1016/ S2215-0366(20)30079-1

5. Duan L, Zhu G (2020) Psychological interventions for people affected by the COVID-19 epidemic. Lancet Psychiatr. https:// doi.org/10.1016/S2215-0366(20)30073-0

6. Cao Y, Li Q, Chen J, Guo X, Miao C, Yang H et al (2020) Hospital emergency management plan during the COVID-19 epidemic. Acad Emerg Med. https://doi.org/10.1111/acem.13951

7. Liu S, Yang L, Zhang C, Xiang YT, Liu Z, Hu S et al (2020) Online mental health services in China during the COVID19 outbreak. Lancet Psychiatr. https://doi.org/10.1016/S2215 $-0366(20) 30077-8$

8. Novel Coronavirus Pneumonia Emergency Response Epidemiology (2020) The epidemiological characteristics of an outbreak of 2019 novel coronavirus diseases (COVID-19) in China. Zhonghua Liu Xing Bing Xue Za Zhi 41(2):145-151. https://doi. org/10.3760/cma.j.issn.0254-6450.2020.02.003(In Chinese)

9. Yao H, Chen JH, Xu YF (2020) Rethinking online mental health services in China during the COVID-19 epidemic. Asian J Psychiatr 50:102015. https://doi.org/10.1016/j.ajp.2020.102015

10. Cui YH (2013) Psychological trauma and crisis intervention in children after earthquake. Zhongguo Dang Dai Er Ke Za Zhi 15(6):423-426 (In Chinese)

11. Gutermann J, Schreiber F, Matulis S, Schwartzkopff L, Deppe J, Steil R (2016) Psychological treatments for symptoms of posttraumatic stress disorder in children, adolescents, and young adults: a meta-analysis. Clin Child Fam Psychol Rev 19(2):77-93. https ://doi.org/10.1007/s10567-016-0202-5
12. CCTV News. Ministry of Education: national elementary and middle school network cloud platform opens for free use today. Feb 17, 2020. https://www.chinanews.com/sh/2020/20022017/9094648.shtml. Accessed Mar 2020 (In Chinese).

13. Wilkinson N, Ang RP, Goh DH (2008) Online video game therapy for mental health concerns: a review. Int J Soc Psychiatr 54(4):370-382. https://doi.org/10.1177/0020764008091659

14. Primack BA, Carroll MV, McNamara M, Klem ML, King B, Rich $M$ et al (2012) Role of video games in improving health-related outcomes: a systematic review. Am J Prev Med 42(6):630-638. https://doi.org/10.1016/j.amepre.2012.02.023

15. China Daily News. How to "save" the strained parent-child relationship during the epidemic of COVID-19. https://cnews.china daily.com.cn/a/202002/14/WS5e47334aa3107bb6b579fb53.html. Accessed 3 Feb 2020 (In Chinese)

16. Zhai Y, Liu K, Zhang L, Gao H, Chen Z, Du S et al (2015) The relationship between post-traumatic symptoms, parenting style, and resilience among adolescents in Liaoning, China: a cross-sectional study. PLoS ONE 10(10):e0141102. https://doi. org/10.1371/journal.pone.0141102

17. Chen Q, Liang M, Li Y, Guo J, Fei D, Wang L et al (2020) Mental health care for medical staff in China during the COVID19 outbreak. Lancet Psychiatr. https://doi.org/10.1016/S2215 -0366(20)30078-X

18. Dong L, Bouey J (2020) Public mental health crisis during COVID-19 pandemic, China. Emerg Infect Dis. https://doi. org/10.3201/eid2607.200407

19. Terrill AL, Hartoonian N, Beier M, Salem R, Alschuler K (2015) The 7-item generalized anxiety disorder scale as a tool for measuring generalized anxiety in multiple sclerosis. Int J MS Care 17(2):49-56. https://doi.org/10.7224/1537-2073.2014-008

20. Lowe B, Unutzer J, Callahan CM, Perkins AJ, Kroenke K (2004) Monitoring depression treatment outcomes with the patient health questionnaire-9. Med Care 42(12):1194-1201. https://doi. org/10.1097/00005650-200412000-00006

21. Cotgrove A (2018) The future of crisis mental health services for children and young people. Child Adolesc Mental Health 23(1):1-3

22. Wu JL, Pan J (2019) The scarcity of child psychiatrists in China. Lancet Psychiatr 6(4):286-287. https://doi.org/10.1016/S2215 -0366(19)30099-9 